\title{
Honokiol inhibits U87MG human glioblastoma cell invasion through endothelial cells by regulating membrane permeability and the epithelial-mesenchymal transition
}

\author{
YOUNG NAK JOO, SO YOUNG EUN, SANG WON PARK, \\ JAE HEUN LEE, KI CHURL CHANG and HYE JUNG KIM \\ Department of Pharmacology, School of Medicine, Institute of Health Sciences, \\ Gyeongsang National University, Jinju, Republic of Korea
}

Received July 22, 2013; Accepted October 16, 2013

DOI: $10.3892 /$ ijo.2013.2178

\begin{abstract}
Glioblastoma is one of the most lethal and prevalent malignant human brain tumors, with aggressive proliferation and highly invasive properties. There is still no effective cure for patients with glioblastoma. Honokiol, derived from Magnolia officinalis, can cross the blood-brain barrier (BBB) and the blood-cerebrospinal fluid barrier (BCSFB), making it a strong candidate for an effective drug for the treatment of brain tumors, including glioblastoma. In our previous study, we demonstrated that honokiol effectively induced apoptotic cell death in glioblastoma. Metastasis poses the largest problem to cancer treatment and is the primary cause of death in cancer patients. Thus, in this study, we investigated the effect of honokiol on the cell invasion process of U87MG human glioblastoma cells through brain microvascular endothelial cells (BMECs) and its possible mechanisms. Honokiol dose-dependently inhibited TNF- $\alpha$-induced VCAM- 1 expression in BMECs and adhesion of U87MG to BMECs. Moreover, honokiol effectively blocked U87MG invasion through BMEC-Matrigel-coated transwell membranes. Increased phosphorylation of VE-cadherin and membrane permeability by TNF- $\alpha$ were suppressed by
\end{abstract}

Correspondence to: Dr Hye Jung Kim, Department of Pharmacology, School of Medicine, Institute of Health Sciences, Gyeongsang National University, 92 Chilam-dong, Jinju 660-551, Republic of Korea

E-mail: hyejungkim@gnu.ac.kr

\begin{abstract}
Abbreviations: BBB, blood-brain barrier; BCSFB, blood cerebrospinal fluid barrier; BMECs, brain microvascular endothelial cells; CAM, cell adhesion molecule; DAPI, 4',6-diamidino-2-phenylindole; ECM, extracellular matrix; ECL, enhanced chemiluminescence; EMT, epithelial-mesenchymal transition; FBS, fetal bovine serum; GBM, glioblastoma multiforme; ICAM, intracellular adhesion molecule; MTT, 3-[4,5-dimethylthiazol-2-yl]-2,5-diphenyltetrazolium bromide; PBS, phosphate-buffered saline; TBS, Tris-buffered saline; TNF, tumor necrosis factor; VCAM, vascular cell adhesion molecule
\end{abstract}

Key words: glioblastoma, endothelial cell, invasion, VCAM-1, VE-cadherin honokiol in BMECs. Furthermore, we investigated the effect of honokiol on the epithelial-mesenchymal transition (EMT) in U87MG cells. Honokiol reduced the expression levels of Snail, N-cadherin and $\beta$-catenin, which are mesenchymal markers, but increased E-cadherin, an epithelial marker. In conclusion, these results suggest that honokiol inhibits metastasis by targeting the interaction between U87MG and BMECs, regulating the adhesion of U87MG to BMECs by inhibiting VCAM-1, and regulating the invasion of U87MG through BMECs by reducing membrane permeability and EMT processes of U87MG cells.

\section{Introduction}

Gliomas are the most common brain tumors of the adult central nervous system. Astrocytomas, which are tumors composed predominantly of neoplastic astrocytes, account for $80-85 \%$ of all gliomas (1). Grade IV astrocytomas, also referred to as glioblastoma multiforme (GBM), is the most common primary malignant brain cancer (2). The proliferation rates of GBM are two to five times higher than grade III tumors, and patients with GBM have a dismal prognosis, with a median survival time of less than 15 months despite aggressive therapy (3). A characteristic of GBM is its ability to infiltrate and invade the surrounding normal brain tissue. Despite advances in techniques for administering radiotherapy, local recurrence of glioblastomas typically leads to patient mortality. Thus, therapies that effectively target invasive glioma cells may significantly improve clinical outcomes.

The underlying molecular mechanisms of brain tumor invasion are complex and involve integrated biochemical processes requiring a coordinated effort of intracellular and extracellular interactions (1). For effective invasion, tumor cells must first detach from the nascent tumor mass and invade the surrounding stroma, which is composed of parenchymal cells and the extracellular matrix (ECM). Cell surface adhesion molecules play an important role in the interaction between the cells and ECM. Cell adhesion molecules (CAMs) are expressed on a variety of cells, including vascular endothelial cells (ECs) and tumor cells (4-7), that have been activated by cytokines such as IL-1 $\alpha$, IL-6 or TNF- $\alpha(8,9)$. Specifically, 
TNF- $\alpha$ induces the upregulation of intracellular adhesion molecule-1 (ICAM-1) and vascular cell adhesion molecule-1 (VCAM-1) in ECs $(10,11)$. ICAM-1 and VCAM-1 have been shown to be involved in cell-cell and cell-ECM interactions and are mechanistically important for the extravasation of cancer cells during metastasis $(12,13)$.

Cadherins are important molecules involved in tumor progression. Different cadherins, including E-cadherin, $\mathrm{N}$-cadherin, T- (or H-) cadherin and VE-cadherin, are reported to have different functions and are expressed in different tissues. E- and N-cadherin are the most thoroughly studied cadherins in terms of the EMT process; the loss of E-cadherin expression in epithelial tumors is associated with a more invasive phenotype and metastasis (14). N-cadherin has been shown to promote cell motility and migration, the opposite effect to that of E-cadherin (14). VE-cadherin is an endothelium-specific member of the cadherin family of adhesion proteins and regulates transmembrane endothelial adherens junctions. Thus, cadherins, including E-cadherin, N-cadherin and VE-cadherin, are involved in tumor metastasis.

Honokiol is a well-known bioactive constituent of the bark of Magnolia officinalis and has been reported to prevent and protect the brain from damage (15) as well as to exert antitumor efficacy in vitro and in vivo (16-19). Notably, treatment with honokiol may be a potential strategy to overcome immunoresistance in glioma (20), as honokiol can cross the BBB and the BCSFB (21). In addition, our previous study demonstrated that honokiol induces apoptotic cell death through the upregulation of the $\mathrm{Bax} / \mathrm{Bcl}-2$ ratio and inhibits invasion through the regulation of ICAM-1 and VCAM-1 in human glioblastoma T98G cells (22). Based on these results, honokiol may represent an effective drug for the treatment of brain tumors, specifically glioblastoma. In this study, we were interested in the effect of honokiol on glioblastoma invasion. Thus, we investigated whether honokiol affects glioblastoma invasion through the regulation of adhesion molecules and VE-cadherin as well as the EMT process in U87MG, a commonly studied grade IV glioma cell line that has been analyzed in at least 1,700 publications over four decades (23).

\section{Materials and methods}

Materials. Honokiol (Fig. 1A) was supplied by Wako Chemical (Wako, Japan). Anti-VCAM-1, anti-VE-cadherin, anti-Snail, anti-N-cadherin, anti- $\beta$-catenin and anti-E-cadherin antibodies were purchased from Santa Cruz Biotechnology (Santa Cruz, CA, USA). Anti-phospho-VE-cadherin (phospho-Y658) antibody was purchased from Abcam (Cambridge, MA, USA). Enhanced chemiluminescence (ECL) western blotting detection reagent was obtained from Amersham (Buckinghamshire, UK). All other chemicals, including Evans blue dye, were purchased from Sigma-Aldrich (St. Louis, MO, USA).

Cell culture. Human glioblastoma cells (U87MGs) and mouse brain microvascular endothelial cells (BMECs) were purchased from ATCC and grown in DMEM medium supplemented with $10 \%$ fetal bovine serum (FBS), 2 mM L-glutamine, $100 \mathrm{IU} / \mathrm{ml}$ penicillin and $10 \mu \mathrm{g} / \mathrm{ml}$ streptomycin and incubated in a humidified $5 \% \mathrm{CO}_{2}$ incubator.
Cell viability assay. Cell viability was determined colorimetrically using a 3-[4,5-dimethylthiazol-2-yl]-2,5-diphenyltetrazolium bromide (MTT) assay. Cells were plated at $1 \times 10^{4}$ cells per well in 24-well plates. After drug treatments, MTT solution was added to each well $(0.1 \mathrm{mg} /$ well $)$ and incubated for $4 \mathrm{~h}$. Supernatants were removed, and formazan crystals in the wells were dissolved in $200 \mu \mathrm{l}$ of dimethyl sulfoxide for $30 \mathrm{~min}$ at $37^{\circ} \mathrm{C}$ and the optical density at $570 \mathrm{~nm}$ was measured using a microplate reader (Bio-Rad, Hercules, CA, USA).

Western blot analysis. Cells were lysed using PRO-PREP protein extraction solution. Aliquots of $40 \mu \mathrm{g}$ of protein were subjected to $10 \%$ SDS-polyacrylamide gel electrophoresis. Separated proteins in SDS-polyacrylamide gel were transferred onto Hybond- $\mathrm{P}^{+}$polyvinylidene difluoride membranes (Amersham Biosciences UK Ltd.). The membrane was blocked with 5\% non-fat milk in Tris-buffered saline containing $0.05 \%$ Tween-20 (TBS-T) for $2 \mathrm{~h}$ at room temperature and the membranes were incubated with the indicated primary antibodies. Proteins were detected with ECL western blotting detection reagent according to the manufacturer's instructions.

Fractionation of cell extracts. The cellular compartment was extracted as previously described with a minor modification (11). Briefly, cells were washed with ice-cold phosphatebuffered saline (PBS; pH 7.4) and lysed in buffer A (10 mM HEPES, pH 8.0, $1.5 \mathrm{mM} \mathrm{MgCl}_{2}, 0.5 \mathrm{mM}$ dithiothreitol and $1 \mathrm{X}$ protease inhibitors). The supernatant (cytoplasmic extract) was obtained by centrifugation at $10,000 \mathrm{x} \mathrm{g}$ for $15 \mathrm{~min}$. The pellets were washed once with buffer $\mathrm{A}$ and resuspended in buffer B (10 mM Tris-Cl, pH 7.5, 0.5\% deoxycholate, EDTA, $0.5 \mathrm{mM}, 0.5 \mathrm{mM}$ dithiothreitol, and $1 \%$ Nonidet P-40). The suspension was agitated for $30 \mathrm{~min}$ at $4{ }^{\circ} \mathrm{C}$ and centrifuged at $10,000 \times \mathrm{g}$ for $20 \mathrm{~min}$. The supernatant fraction containing nuclear proteins was collected.

Adhesion assay. BMECs were treated with honokiol for $24 \mathrm{~h}$ and subsequently stimulated with TNF- $\alpha$ for $6 \mathrm{~h}$. Thereafter, U87MG $1 \times 10^{6}$ cells were added to BMEC layers. After $30 \mathrm{~min}$, cell suspensions were removed, and BMECs were gently washed with DMEM medium. The cells were counted under a light microscope, and images were taken using an Olympus microscope (CKX41) equipped with a camera (Nikon, DS-U3).

Matrigel invasion assay. The Matrigel invasion assays were performed in two ways. First, the insert wells $(8-\mu \mathrm{m}$ pore size, BD Falcon, Franklinlakes, NJ, USA) were coated with $100 \mu \mathrm{l}$ of Matrigel (1 mg/ml, BD Falcon), and BMECs were then added $\left(2 \times 10^{5}\right.$ cells per well). After $2 \mathrm{~h}, \mathrm{U} 87 \mathrm{MG}$ cells $\left(2 \times 10^{5}\right)$ that had been pretreated with honokiol for $24 \mathrm{~h}$ were added to the BMEC layers on Matrigel in the inserts. The inserts were incubated for $24 \mathrm{~h}$ in a $37^{\circ} \mathrm{C}$ cell culture incubator. In the second method, BMECs were pretreated with honokiol for $24 \mathrm{~h}$ and then washed with PBS three times. After BMECs were stimulated with TNF- $\alpha$ for $6 \mathrm{~h}, \mathrm{U} 87 \mathrm{MG}$ cells were added to BMEC-Matrigel coated wells and incubated for $24 \mathrm{~h}$. The non-invasive cells that remained on the upper side of the insert were removed. The cells on the lower part of insert membranes were stained with 4',6-diamidino-2-phenylindole (DAPI) and counted under a light microscope. 
A<smiles>C=CCc1cc(CC=C)c(-c2ccc(O)c(O)c2)cc1O</smiles>

B
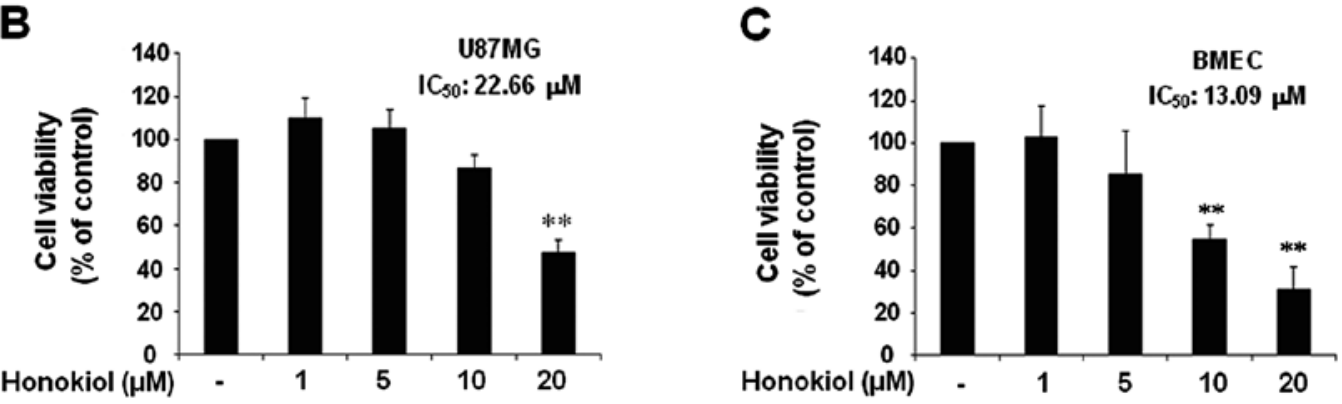

Figure 1. The effect of honokiol on the viability of U87MG cells and BMECs. (B and C) Cells were treated with the indicated concentrations of honokiol for $24 \mathrm{~h}$. Cell viability was determined by the MTT assay. All data represent mean values \pm SEM of three independent experiments in a triplicate assay. Significant compared with control, ${ }^{* *} \mathrm{P}<0.01$.

Membrane permeability study. Cell culture inserts $(0.4-\mu \mathrm{m}$ pore size, BD Falcon) were placed in a 24 -well plate. BMECs were seeded on the inserts and treated with honokiol for $1 \mathrm{~h}$. The cells were washed with PBS and treated with TNF- $\alpha$. Four hours later, the media were removed, the cells were washed with PBS and $100 \mu \mathrm{l}$ of $200 \mu \mathrm{g} / \mathrm{ml}$ Evans blue suspended in $0.1 \%$ bovine serum albumin in transport buffer (10 mM HEPES, $132 \mathrm{mM} \mathrm{NaCl}, 4 \mathrm{mM} \mathrm{KCl}, 1.4 \mathrm{mM} \mathrm{MgCl}$, $1.2 \mathrm{mM} \mathrm{H}_{3} \mathrm{PO}_{4}, 1 \mathrm{mM} \mathrm{CaCl}_{2}, 4.5 \%$ glucose, $\mathrm{pH}$ 7.4) was added to the upper chamber (insert wells). After $4 \mathrm{~h}$, aliquots (100 $\mu \mathrm{l})$ were collected from the lower chamber (24-well plate). Molecular permeability across the membrane was determined by measuring optical density of Evans blue at $620 \mathrm{~nm}$ using an EIA reading photometer (US.HL 5500P0, Bio-Rad).

Statistical analysis. Scanning densitometry was performed using Image Master ${ }^{\circledR}$ VDS (Pharmacia Biotech Inc., San Francisco, CA, USA). All results are representative of three independent experiments performed in triplicate (mean \pm SEM). Significant differences within data were evaluated by one-way analysis of variance (ANOVA) and the post hoc test by Scheffe. P-values $<0.05$ were treated as statistically significant.

\section{Results}

The effect of honokiol on the cell viability of U87MG human glioblastoma cells and BMECs. In this study, we aimed to investigate the effect of honokiol on the cell invasion process of U87MG human glioblastoma cells through brain microvascular endothelial cells (BMECs) and its possible mechanisms. Thus, first, we examined the cell viability of U87MG cells and BMECs in response to honokiol in a lower range compared to the previous study (22). When U87MG cells and BMECs were treated with indicated honokiol
(1-20 $\mu \mathrm{M})$ for $24 \mathrm{~h}$, the results revealed that honokiol significantly decreased the cell viability of U87MG only at doses of $20 \mu \mathrm{M}$ (Fig. 1B). BMECs exhibited significant reduction in viability at concentrations of $10 \mu \mathrm{M}$ and $20 \mu \mathrm{M}$ (Fig. 1C). Honokiol-mediated cytotoxicity was not significant at doses $<20 \mu \mathrm{M}$ in U87MGs or $10 \mu \mathrm{M}$ in BMECs. The $\mathrm{IC}_{50}$ of honokiol in U87MG and BMECs was 22.66 and $13.09 \mu \mathrm{M}$, respectively.

Honokiol inhibited VCAM-1 expression by TNF- $\alpha$ in BMECs and suppressed the adhesion of U87MG cells to TNF- $\alpha$ stimulated BMECs. Cell-cell and cell-ECM interactions are partially regulated by adhesion molecules. Specifically, VCAM-1 has been shown to be important in cancer cell metastasis $(24,25)$. Accordingly, we examined whether honokiol inhibits VCAM-1 expression by TNF- $\alpha$ in BMECs. BMECs exhibited a significant induction of VCAM-1 protein levels in response to TNF- $\alpha(10 \mathrm{ng} / \mathrm{ml}, 6 \mathrm{~h})$, which was efficiently inhibited by pretreatment with honokiol; significant inhibition occurred at 5-20 $\mu \mathrm{M}$ honokiol (Fig. 2A). Next, we investigated the effect of honokiol on U87MG adhesion to BMECs. Adhesion of U87MG cells to BMECs stimulated with TNF- $\alpha$ at $10 \mathrm{ng} / \mathrm{ml}$ for $6 \mathrm{~h}$ was dramatically increased compared to unactivated BMECs. In contrast, treatment of the BMECs with 5-20 $\mu \mathrm{M}$ honokiol for $24 \mathrm{~h}$ before TNF- $\alpha$ stimulation resulted in a significant reduction of adhesion of U87MG cells to ECs (Fig. 2B and C).

Honokiol reduces TNF- $\alpha$-mediated phosphorylation of $V E$-cadherin and increases membrane permeability in BMECs. Tyrosine phosphorylation of VE-cadherin is known to be associated with weak junctions and impaired barrier function. Therefore, we investigated the effect of honokiol on the phosphorylation of VE-cadherin at tyrosine residue 658 (Y658) by western blotting. When BMECs were treated with TNF- $\alpha$ 
A

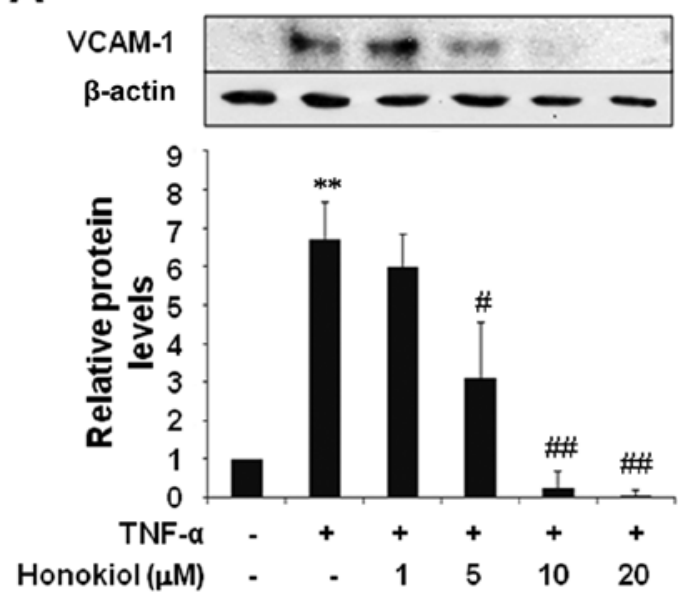

B

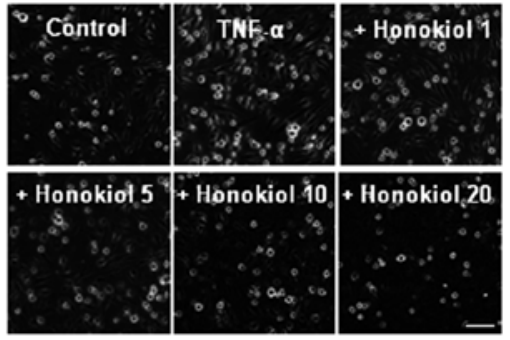

(Scale bar: $100 \mu \mathrm{m}$ )

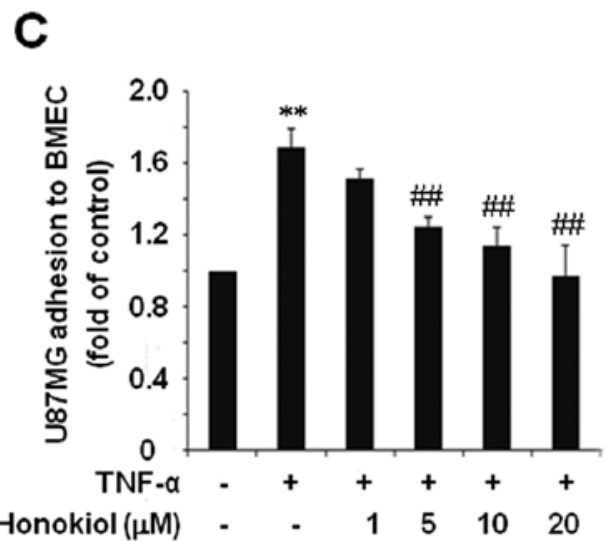

Figure 2. Honokiol inhibits VCAM-1 expression by TNF- $\alpha$ in BMECs as well as U87MG cell adhesion to TNF- $\alpha$-treated BMECs. (A) BMECs were cultured with honokiol for $24 \mathrm{~h}$ and then stimulated with TNF- $\alpha(10 \mathrm{ng} / \mathrm{ml})$ for $6 \mathrm{~h}$. The expression of VCAM-1 and $\beta$-actin was analyzed by western blot analysis. (B and C) After BMECs were pretreated with honokiol for $24 \mathrm{~h}$, the cells were activated with TNF- $\alpha$ for 6 h. Subsequently, U87MG cells were added to the BMECs for $30 \mathrm{~min}$. The remaining cell suspension was withdrawn and the number of adherent cells was quantified under a light microscope. All data represent mean values \pm SEM of three independent experiments in a triplicate assay. Significant compared to the control, ${ }^{* *} \mathrm{P}<0.01 ;$ significant compared to TNF- $\alpha$, ${ }^{\#} \mathrm{P}<0.01$

in a time-dependent manner, TNF- $\alpha$ was able to prominently increase phospho-VE-cadherin at $4 \mathrm{~h}$ (preliminary data, not shown). Thus, we measured the phospho-VE-cadherin levels at $4 \mathrm{~h}$ after TNF- $\alpha$ treatment. Honokiol treatment $1 \mathrm{~h}$ prior to TNF- $\alpha$ significantly decreased TNF- $\alpha$-induced phospho-VEcadherin at very low dose $(1 \mu \mathrm{M})$ (Fig. 3A). This result coincided with the membrane permeability results. The concentration of Evans blue dye across BMECs increased with TNF- $\alpha$ treatment and significantly decreased with honokiol treatment $(1-20 \mu \mathrm{M})$. TNF- $\alpha$-induced membrane permeability was significantly reduced with $20 \mu \mathrm{M}$ of honokiol, however, the permeability remained slightly higher than with $10 \mu \mathrm{M}$ of honokiol, possibly due to cell toxicity caused by $20 \mu \mathrm{M}$ honokiol (Fig. 3B).

Honokiol inhibits EMT in U87MG cells via downregulation of the mesenchymal markers Snail, $\beta$-catenin and $N$-cadherin and the upregulation of the epithelial marker E-cadherin. Then, we assessed whether honokiol regulates EMT proteins, including Snail, $\beta$-catenin, N-cadherin and E-cadherin. Honokiol effectively reduced the mesenchymal markers Snail, $\beta$-catenin and $\mathrm{N}$-cadherin but increased the levels of the epithelial marker E-cadherin. These results suggest that honokiol suppresses EMT by downregulating the mesenchymal markers Snail, $\beta$-catenin and $\mathrm{N}$-cadherin and upregulating the epithelial marker E-cadherin (Fig. 4).

Honokiol effectively inhibits U87MG invasion through BMECs. We evaluated the effect of honokiol on human glioblastoma
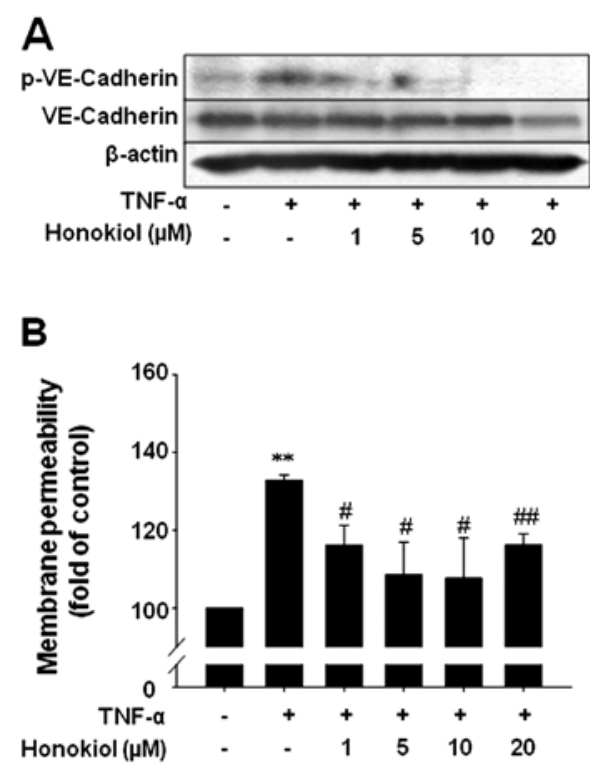

Figure 3. Honokiol inhibits TNF- $\alpha$-mediated phosphorylation of VE-cadherin and reduces membrane permeability in BMECs. (A) BMECs were pretreated with honokiol for $1 \mathrm{~h}$, followed by incubation with TNF- $\alpha$ for $4 \mathrm{~h}$. VE-cadherin expression and phosphorylation of VE-cadherin (Y658) were determined by western blot analysis. (B) BMECs were seeded on the inserts. The cells were treated as described in (A). After treatment, Evans blue was added to the upper chamber of the inserts. Four hours later, aliquots were sampled from the lower chamber and the optical density (OD) was measured at $620 \mathrm{~nm}$. Data represent the mean values \pm SEM of four independent experiments. Significant compared to the control; ${ }^{* *} \mathrm{P}<0.01$, significant compared with TNF- $\alpha,{ }^{\#} \mathrm{P}<0.05 ;{ }^{\# \#} \mathrm{P}<0.01$. 

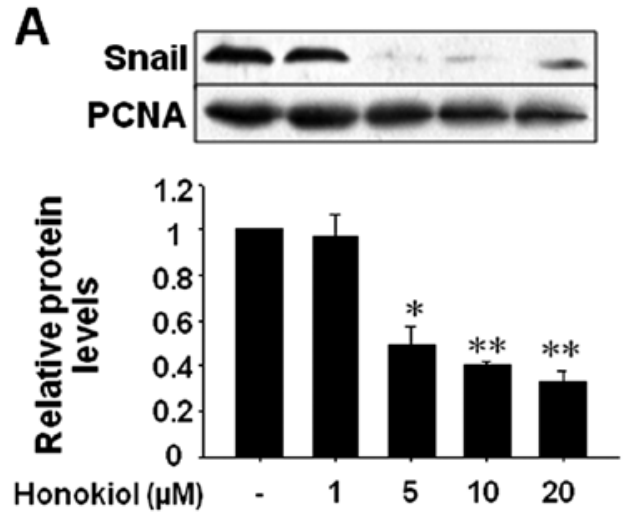

B
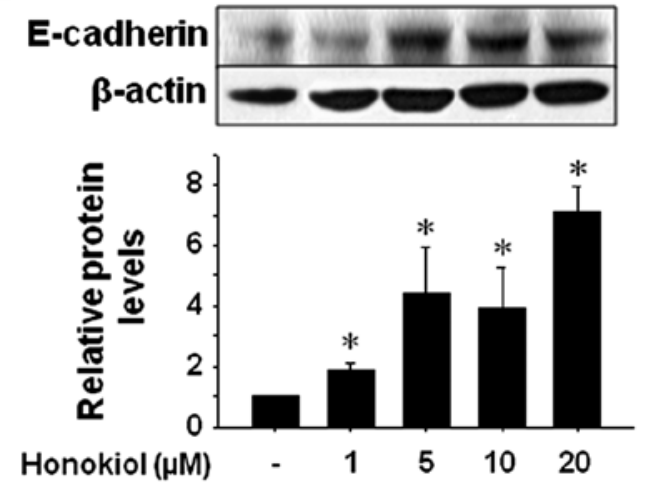

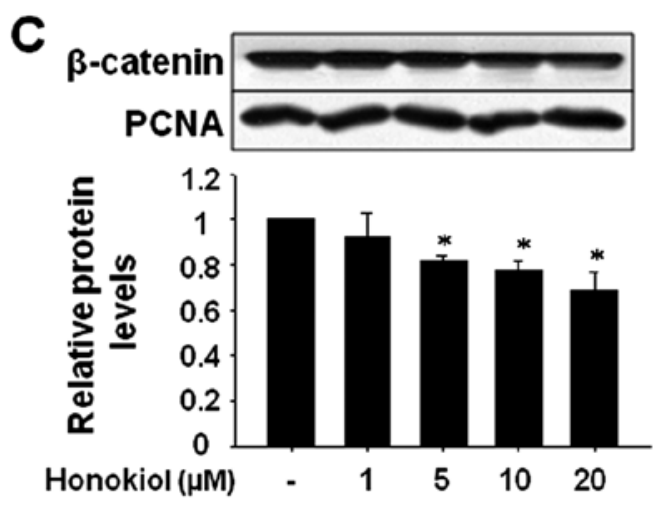

D

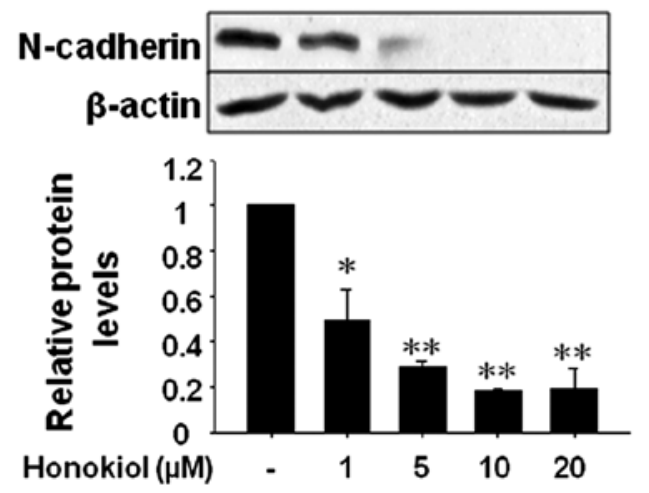

Figure 4. Honokiol downregulates the mesenchymal markers Snail, $\beta$-catenin and N-cadherin but upregulates the epithelial marker E-cadherin. U87MG cells were treated with honokiol for $24 \mathrm{~h}$, and the levels of Snail (A) and $\beta$-catenin (C) in nuclear fractions and the E-cadherin (B) and N-cadherin (D) levels in cytosolic fractions were determined by western blot analysis. Data are presented as the mean values \pm SEM of three independent experiments. Significant compared to the control, ${ }^{*} \mathrm{P}<0.05 ;{ }^{* *} \mathrm{P}<0.01$.

invasion through BMECs using two different methods. First, to test the effect of honokiol on U87MG invasion through the regulation of EMT, U87MG cells were treated with honokiol in a dose-dependent manner and added to BMECs that were not treated with honokiol or TNF- $\alpha$ (Fig. 5A). In our second method, BMECs were treated with honokiol and stimulated with TNF- $\alpha$ and incubated with U87MG cells that were not treated with honokiol to examine the effect of honokiol on U87MG invasion through the regulation of VCAM-1 and membrane permeability in BMECs (Fig. 5D). As expected, U87MG cells treated with honokiol exhibited reduced invasion through BMECs (Fig. 5B and C). In addition, treatment of BMECs with honokiol suppressed U87MG cell invasion through TNF- $\alpha$-stimulated BMECs (Fig. 5E and F).

\section{Discussion}

Glioblastoma is almost uniformly fatal with only a few patients surviving longer than 2 years (26). Two major problems impede the success of chemotherapy. First, the delivery of sufficient amounts of most antineoplastic drugs into brain tissue is prevented by the BBB. Second, high-grade gliomas are often characterized by high intrinsic chemoresistance. Honokiol is reported to cross the $\mathrm{BBB}$ and the $\mathrm{BCSFB}$ and to overcome immunoresistance in glioma, strongly suggesting that it could be an effective drug for the treatment of brain tumors, including glioblastoma. Our previous study demonstrated that honokiol induced apoptotic cell death and inhibited cell invasion through regulation of ICAM-1 and VCAM-1 in human glioblastoma T98G cells (22). Recently, it was reported that tumors, including gliomas, contain a small subpopulation of cancer stem cells (CSCs). These cells are characterized by their ability to form neural spheres, antibiotic resistance and high cell migration ability (27). According to Moon and Park (28), U87MG cells formed neural spheres and expressed CD133 and Bmil, which are the canonical cell surface markers of brain CSCs, at much higher levels than any other glioblastomas (A172, T98G, U138, U251, U373). Given these characteristics of U87MG, finding new treatments that can target this cell type may be beneficial in developing an effective cure for glioblastoma. Therefore, we further investigated the effect of honokiol on U87MG human glioblastoma cell invasion and the possible mechanisms underlying this regulation by honokiol. Our results revealed that honokiol effectively inhibited the adhesion of U87MG cells to BMECs by inhibiting normal VCAM-1 expression. Honokiol also perturbed U87MG invasion through BMECs by inhibiting VCAM-1 expression and suppressing phospho-VE-cadherin-mediated BMEC permeability. TNF- $\alpha$-induced permeability of BMECs was significantly reduced by $1 \mu \mathrm{M}$ honokiol; however, permeability appeared to increase slightly at $20 \mu \mathrm{M}$, possibly due to the cytotoxicity of honokiol at $20 \mu \mathrm{M}$. 
A

B
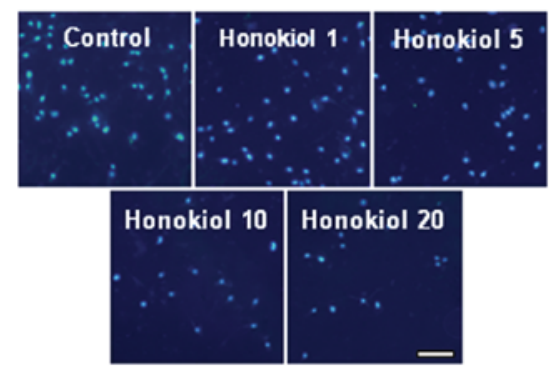

(Scale bar : $100 \mu \mathrm{m}$ )

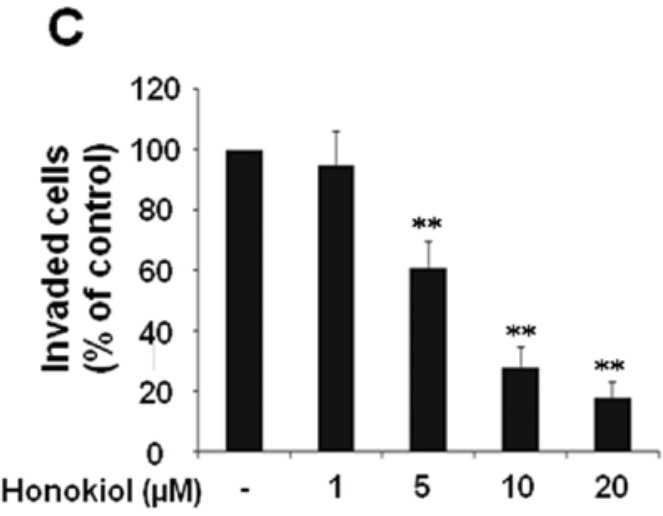

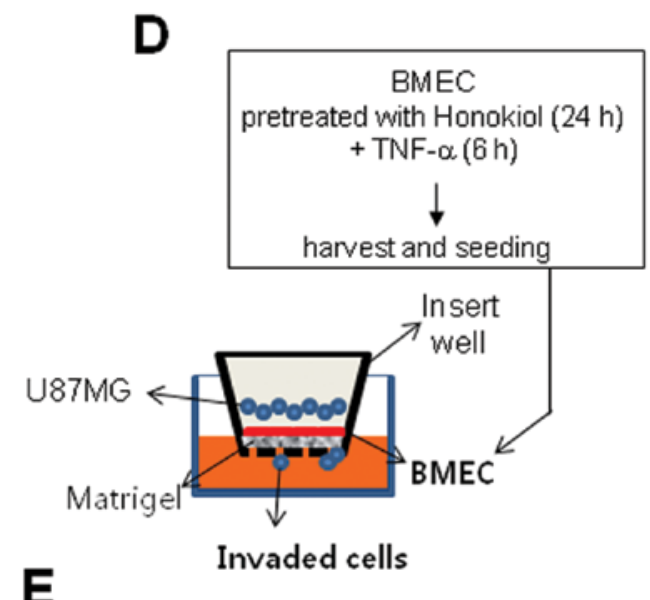

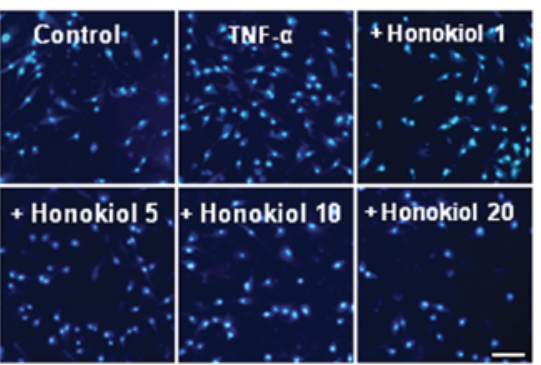

(Scale bar : $100 \mu \mathrm{m}$ )

$\mathbf{F}$

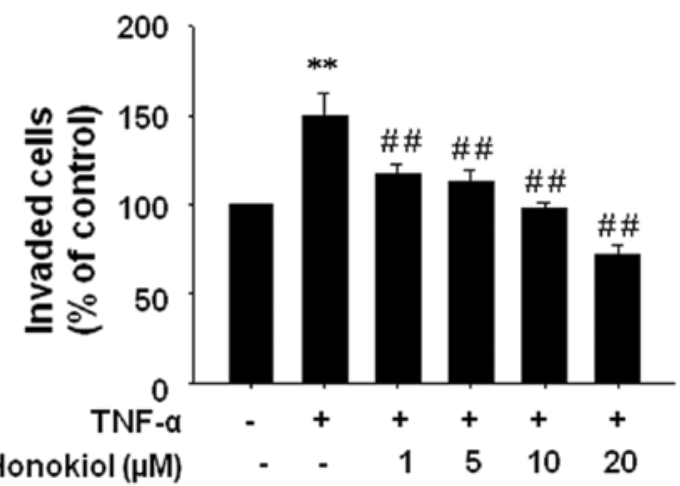

Figure 5. Honokiol inhibits the invasion of human glioblastoma U87MG cells through BMECs. (A-C) BMECs were added to the Matrigel coated insert wells. U87MG cells were pretreated with honokiol for $24 \mathrm{~h}$, harvested and added onto BMECs as described in Materials and methods. (D-F) BMECS that had been treated with honokiol for $24 \mathrm{~h}$ were added to Matrigel coated inserts wells. After $2 \mathrm{~h}$, U87MG cells were added to BMEC-Matrigel coated inserts. The inserts were incubated for $24 \mathrm{~h}$ in a $37^{\circ} \mathrm{C}$ cell culture incubator. The non-invasive cells that remained on the upper side of the insert were removed and the cells on the lower part of insert membranes were stained with DAPI and counted under a fluorescence microscope. Values represent the means \pm SEM of 3 independent experiments (significant compared to the control, ${ }^{* *} \mathrm{P}<0.01$ ).

As mentioned above, glioblastoma exhibits aggressive proliferation and highly invasive properties and can diffusely infiltrate various regions of the normal brain, accounting for a poor prognosis. Tumor invasion results from vasculature leakiness and the directional migration of tumor cells across a disrupted endothelium; thus, cancer metastasis requires communication between tumor cells and ECs that culminates in the disruption of EC-EC contacts and the degradation of the vascular basement membrane. Cell surface adhesion molecules play an important role in the interaction between the cells and ECM, and some highly metastatic human melanoma cells adhere and migrate to VCAM-1 rather than ICAM-1 (24). In addition, endothelial permeability is a major factor influencing intravasation, extravasation and invasion in cancer metastasis. Endothelial cells possess several molecular mechanisms by which vascular permeability can be modulated. Such mechanisms focus on adherens junction organization, and in several cases, target VE-cadherin specifically. Furthermore, the phosphorylation, cleavage and internalization of VE-cadherin are thought to affect endothelial permeability (29). In this study, honokiol inhibited U87MG cell invasion across ECs through the downregulation of VCAM-1 expression and the inhibition of phospho-VE-cadherin-mediated EC permeability.

In addition, loss of E-cadherin expression in epithelial tumors is associated with a more invasive phenotype and metastasis (14). $\mathrm{N}$-cadherin has been shown to promote cell 


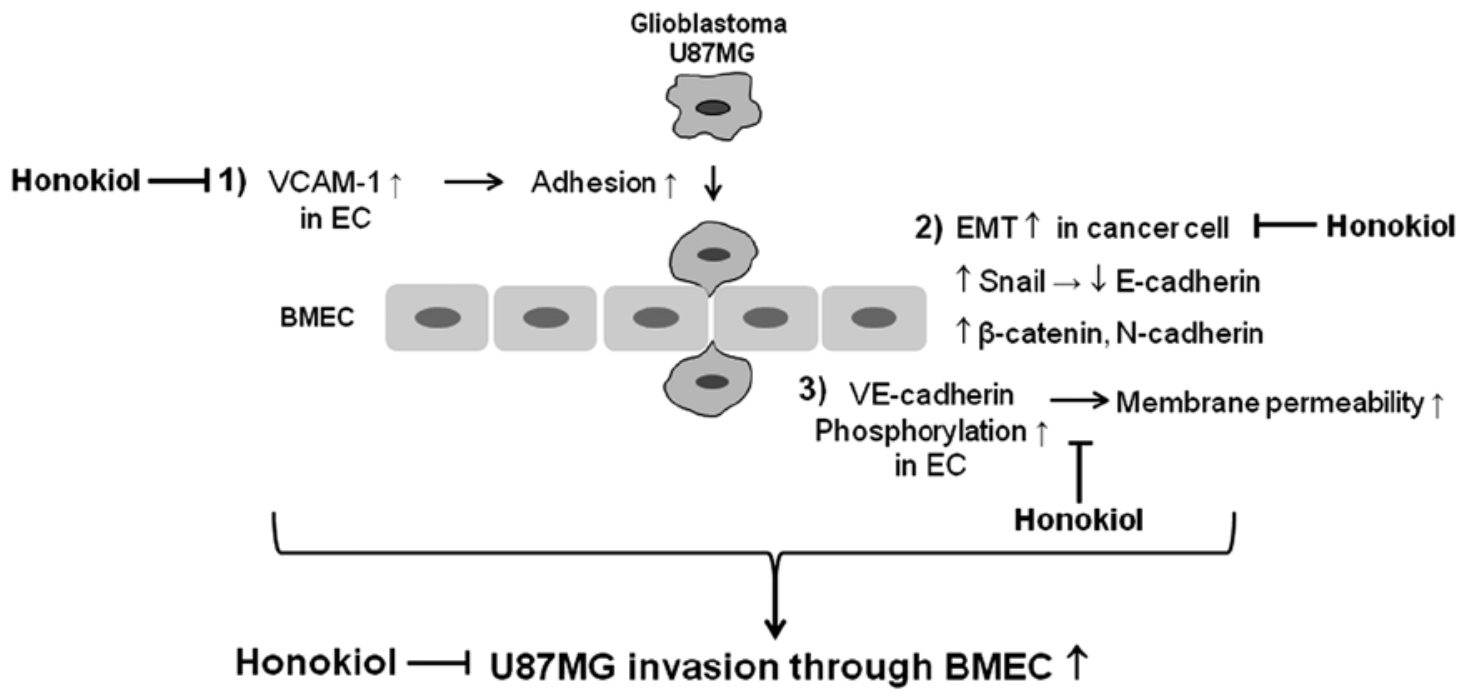

Figure 6. Schematic representation of the proposed model of the anti-metastatic effects of honokiol in glioblastoma U87MG cells. Honokiol inhibits the adhesion of cancer cells to ECs by downregulating adhesion molecules (VCAM-1) and inhibits the invasion of cancer cells through EC cells by reducing membrane permeability and EMT, thereby inhibiting metastasis.

motility and migration, an effect opposite to that of E-cadherin (14). The cadherin switch may occur during the transition from a benign to an invasive, malignant tumor phenotype. All gliomas, regardless of grade, lack E-cadherin expression (1). Concerning the upstream signals that affect $\mathrm{N}$ - and E-cadherin, Snail suppresses transcription of E-cadherin, and $\beta$-catenin induces $\mathrm{N}$-cadherin expression. Snail and $\beta$-catenin are negatively regulated by GSK-3 $\beta$, which is regulated by intracellular signaling pathways including PI3K/Akt. In other words, activation of PI3K/Akt results in the phosphorylation of GSK-3 $\beta$ (inactivation of GSK-3 $\beta$ ), which in turn increases Snail and $\beta$-catenin protein levels. In this study, honokiol significantly reduced $\mathrm{N}$-cadherin levels but increased E-cadherin levels in cytosolic fractions. In addition, honokiol decreased both Snail and $\beta$-catenin levels in nuclear fractions. These results suggest that honokiol suppresses EMT through the reduction of both Snail and $\beta$-catenin levels, which results in the suppression of $\mathrm{N}$-cadherin and the induction of E-cadherin. Further study is needed to examine whether honokiol may decrease the phosphorylation of Akt while increasing the phosphorylation of GSK-3 $\beta$.

Taken together, our findings suggest that honokiol exhibits an inhibitory effect on the process of metastasis by targeting the interaction between U87MG and BMECs; honokiol regulates the adhesion of U87MG cells to BMECs by inhibiting VCAM-1 expression in BMECs, and reduces the invasion of U87MG cells through BMECs by reducing BMEC permeability and inhibiting EMT in U87MG. These findings suggest that honokiol may serve as a therapeutic strategy against brain tumors such as glioblastoma.

\section{Acknowledgements}

This study was supported by Basic Science Research Program through the National Research Foundation of Korea (NRF) funded by the Ministry of Education, Science and Technology (2012R1A1A3003268) and by the MRC program of MOST/ KOSEF (NRF-2005-0049415).

\section{References}

1. Nakada M, Nakada S, Demuth T, Tran NL, Hoelzinger DB and Berens ME: Molecular targets of glioma invasion. Cell Mol Life Sci 64: 458-478, 2007.

2. Clark MJ, Homer N, O'Connor BD, Chen Z, Eskin A, Lee H, Merriman B and Nelson SF: U87MG decoded: the genomic sequence of a cytogenetically aberrant human cancer cell line. PLoS Genet 6: e1000832, 2010.

3. Stupp R, Mason WP, van den Bent MJ, Weller M, Fisher B, Taphoorn MJ, Belanger K, Brandes AA, Marosi C, Bogdahn U, Curschmann J, Janzer RC, Ludwin SK, Gorlia T, Allgeier A, Lacombe D, Cairncross JG, Eisenhauer E and Mirimanoff RO: European Organisation for Research and Treatment of Cancer Brain Tumor and Radiotherapy Groups; National Cancer Institute of Canada Clinical Trials Group. Radiotherapy plus concomitant and adjuvant temozolomide for glioblastoma. N Engl J Med 352: 987-996, 2005.

4. Fox SB, Turner GD, Gatter KC and Harris AL: The increased expression of adhesion molecules ICAM-3, E-selectin and P-selectins on breast cancer endothelium. J Pathol 177: 369-376, 1995.

5. Nizamutdinova IT, Lee GW, Lee JS, Cho MK, Son KH, Jeon SJ, Kang SS, Kim YS, Lee JH, Seo HG, Chang KC and Kim HJ: Tanshinone I suppresses growth and invasion of human breast cancer cells, MDA-MB-231, through regulation of adhesion molecules. Carcinogenesis 29: 1885-1892, 2008.

6. Christiansen I, Sundstrom C and Totterman TH: Elevated serum levels of soluble vascular cell adhesion molecule-1 (sVCAM-1) closely reflect tumour burden in chronic B-lymphocytic leukaemia. Br J Haematol 103: 1129-1137, 1998.

7. Maeda K, Kang SM, Sawada T, Nishiguchi Y, Yashiro M, Ogawa Y, Ohira M, Ishikawa T and Hirakawa-YS Chung K: Expression of intercellular adhesion molecule-1 and prognosis in colorectal cancer. Oncol Rep 9: 511-514, 2002.

8. Becker JC, Dummer R, Hartmann AA, Burg G and Schmidt RE: Shedding of ICAM-1 from human melanoma cell lines induced by IFN-gamma and tumor necrosis factor-alpha. Functional consequences on cell-mediated cytotoxicity. J Immunol 147: 4398-4401, 1991

9. Osborn L, Hession C, Tizard R, Vassallo C, Luhowskyj S, Chi-Rosso G and Lobb R: Direct expression cloning of vascular cell adhesion molecule-1, a cytokine-induced endothelial protein that binds to lymphocytes. Cell 59: 1203-1211, 1989.

10. Kim HJ, Tsoy I, Park JM, Chung JI, Shin SC and Chang KC: Anthocyanins from soybean seed coat inhibit the expression of TNF- $\alpha$-induced genes associated with ischemia/reperfusion in endothelial cell by NF- $\mathrm{B}$-dependent pathway and reduce rat myocardial damages incurred by ischemia and reperfusion in vivo. FEBS Lett 580: 1391-1397, 2006. 
11. Nizamutdinova IT, Oh HM, Min YN, Park SH, Lee MJ, Kim JS Yean MH, Kang SS, Kim YS, Chang KC and Kim HJ: Paeonol suppresses intercellular adhesion molecule-1 expression in tumor necrosis factor- $\alpha$-stimulated human umbilical vein ECs by blocking p38, ERK and nuclear factor- $\mathrm{\kappa B}$ signaling pathways. Int Immunopharmacol 7: 343-350, 2007.

12. Thompson EW and Price JT: Mechanisms of tumour invasion and metastasis: emerging targets for therapy. Expert Opin Ther Targets 6: 217-233, 2002.

13. Balkwill $\mathrm{F}$ and Mantovani A: Inflammation and cancer: back to Virchow? Lancet 357: 539-545, 2001.

14. Cavallaro U and Christofori G: Cell adhesion and signalling by cadherins and Ig-CAMs in cancer. Nat Rev Cancer 4: 118-132, 2004.

15. Liou KT, Shen YC, Chen CF, Tsao CM and Tsai SK: Honokiol protects rat brain from focal cerebral ischemia-reperfusion injury by inhibiting neutrophil infiltration and reactive oxygen species production. Brain Res 992: 159-166, 2003.

16. Hibasami H, Achiwa Y, Katsuzaki H, Imai K, Yoshioka K Nakanishi K, Ishii Y, Hasegawa $M$ and Komiya T: Honokiol induces apoptosis in human lymphoid leukemia molt 4B cells. Int J Mol Med 2: 671-673, 1998.

17. Yang SE, Hsieh MT, Tsai TH and Hsu SL: Downmodulation of $\mathrm{Bcl}-\mathrm{XL}$, release of cytochrome $\mathrm{c}$ and sequential activation of caspases during honokiol induced apoptosis in human squamous lung cancer $\mathrm{CH} 27$ cells. Biochem Pharmacol 63: 1641-1651, 2002.

18. Wang T, Chen F, Chen Z, Wu YF, Xu XL, Zheng S and Hu X: Honokiol induces apoptosis through p53-independent pathway in human colorectal cell line RKO. World J Gastroenterol 10 2205-2208, 2004

19. Hirano T, Gotoh M and Oka K: Natural flavonoids and lignans are potent cytostatic agents against human leukemic HL-60 cells. Life Sci 55: 1061-1069, 1994

20. Crane C, Panner A, Pieper RO, Arbiser J and Parsa AT: Honokiolmediated inhibition of PI3K/mTOR pathway: a potential strategy to overcome immunoresistance in glioma, breast, and prostate carcinoma without impacting T cell function. J Immunother 32: 585-592, 2009
21. Wang X, Duan X, Yang G, Zhang X, Deng L, Zheng H, Deng C, Wen J, Wang N, Peng C, Zhao X, Wei Y and Chen L: Honokiol crosses BBB and BCSFB, and inhibits brain tumor growth in rat 9L intracerebral gliosarcoma model and human U251 xenograft glioma model. PLoS One 6: e18490, 2011.

22. Jeong JJ, Lee JH, Chang KC and Kim HJ: Honokiol exerts an anticancer effect in T98G human glioblastoma cells through the induction of apoptosis and the regulation of adhesion molecules. Int J Oncol 41: 1358-1364, 2012.

23. Ponten J and Macintyre EH: Long term culture of normal and neoplastic human glia. Acta Pathol Microbiol Scand 74: 465-486, 1968.

24. Klemke M, Weschenfelder T, Konstandin MH and Samstag Y: High affinity interaction of integrin alpha4beta1 (VLA-4) and vascular cell adhesion molecule 1 (VCAM-1) enhances migration of human melanoma cells across activated endothelial cell layers. J Cell Physiol 212: 368-374, 2007.

25. Wu TC: The role of vascular cell adhesion molecule-1 in tumor immune evasion. Cancer Res 67: 6003-6006, 2007.

26. Davis FG, Freels S, Grutsch J, Barlas S and Brem S: Survival rates in patients with primary malignant brain tumors stratified by patient age and tumor histological type: analysis based on surveillance, epidemiology and end results (SEER) data, 1973-1991. J Neurosurg 88: 1, 1998.

27. Singh SK, Clarke ID, Terasaki M, Bonn VE, Hawkins C, Squire J and Dirks PB: Identification of a cancer stem cell in human brain tumors. Cancer Res 63: 5821-5828, 2003.

28. Moon SH and Park KS: Enrichment of cancer stem cell of glioblastoma by neurosphere formation. Tissue Eng Regenerative Med 9: 40-47, 2012.

29. Dejana E, Orsenigo F and Lampugnani MG: The role of adherens junctions and VE-cadherin in the control of vascular permeability. J Cell Sci 121: 2115-2122, 2008. 